\title{
Single-session EUS-guided hepaticogastrostomy and dual-scope gastroenterostomy: a modified technique for palliative double endoscopic biliary and gastric bypass
}

A 59-year-old man with unresectable ampullary adenocarcinoma causing gastric outlet and biliary obstruction was palliated by placement of biliary and duodenal self-expandable metal stents (SEMSs). His symptoms relapsed 4 months later and tumor ingrowth was noted through both SEMSs at endoscopy. Single-session endoscopic ultrasound (EUS)-guided biliary drainage and EUSguided gastroenterostomy were undertaken.

EUS-guided hepaticogastrostomy was performed first. A curved linear-array echoendoscope was positioned in the upper gastric body. A 19-gauge needle was used to puncture the left intrahepatic bile duct, with access being confirmed by aspiration of bile and by cholangiography. A 0.035-inch guidewire was advanced through the needle. A 6-mm biliary balIoon dilator was used to dilate the tract, and this was followed by transgastric placement of a $10-\mathrm{mm} \times 10-\mathrm{cm}$ fully-covered SEMS, which was then clipped to the gastric mucosa.

A 7-mm pediatric endoscope was next introduced into the proximal jejunum through the duodenal SEMS, which was partially blocked by tumor ingrowth. Water was instilled through the scope to distend the jejunal lumen. With the echoendoscope placed in the gastric cavity alongside the pediatric endoscope, the water-filled jejunal loop was identified by EUS and punctured with a 19-gauge needle. A 0.035-inch guidewire was passed through the needle and grasped with a forceps that was passed through the pediatric scope. A Hot Axios delivery system was inserted over the wire, while traction was maintained on both ends of the guidewire. The distal end of the stent delivery system was inserted through the stomach wall into the jejunal lumen by applying electrocautery. The lumenapposing metal stent was then deployed under combined EUS, fluoroscopic, and endoscopic guidance. Maximal opening

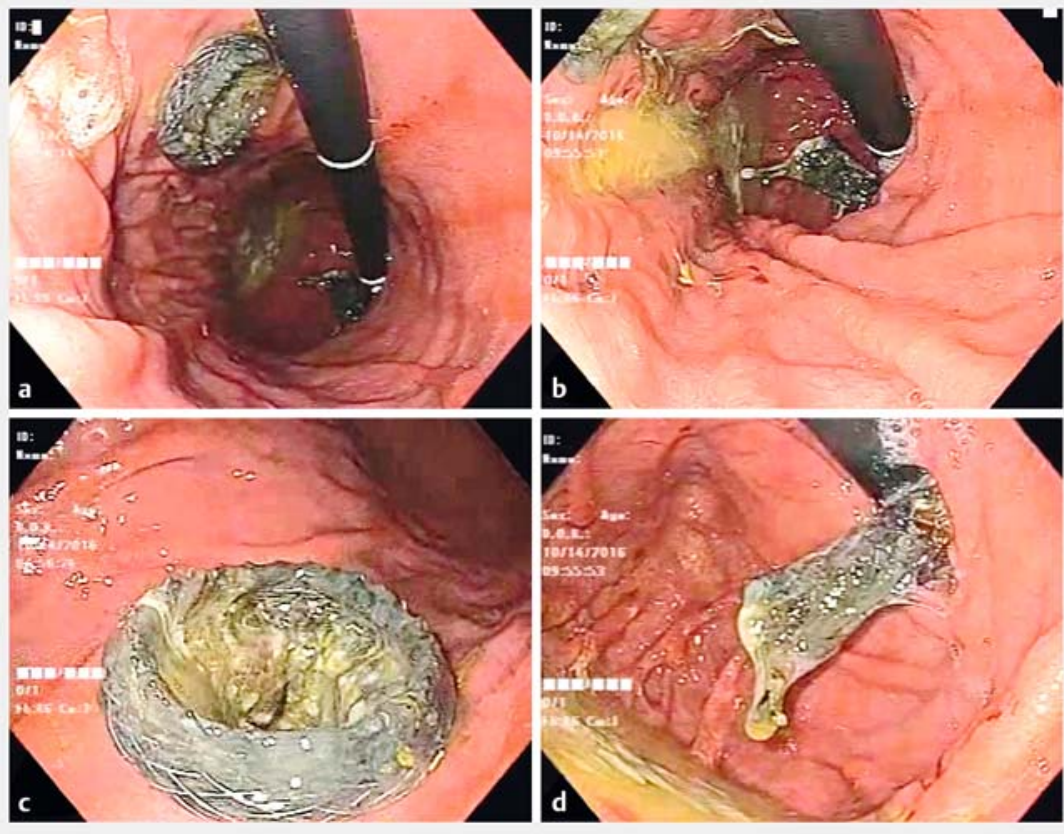

- Fig. 1 Images from the follow-up endoscopy showing: a, b both stents remaining in situ; c the gastroenteric lumen-apposing stent is in situ and patent; $\mathbf{d}$ the hepaticogastrostomy stent is in situ and patent.
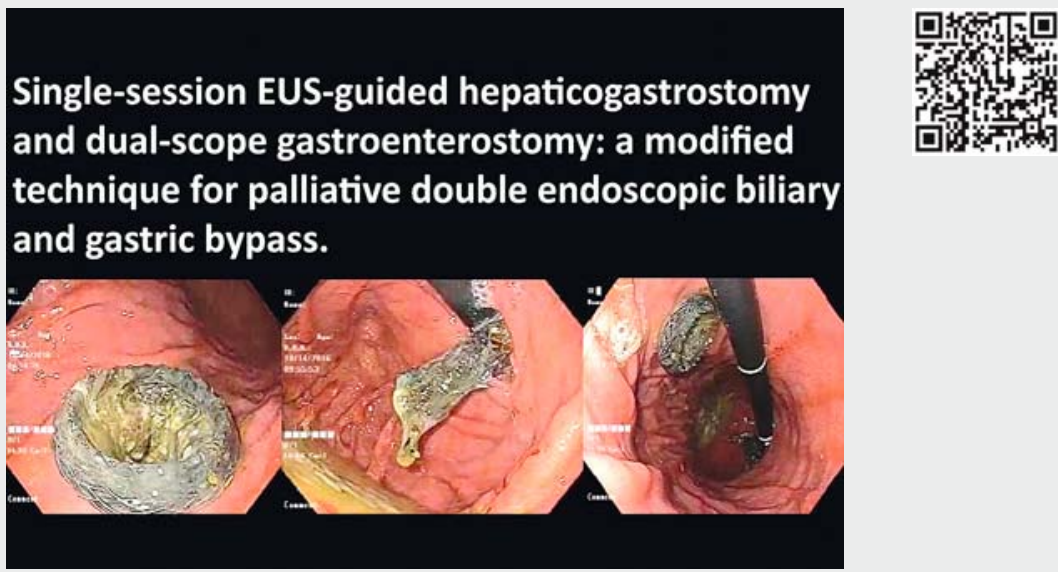

Video 1 The video shows step by step the creation of the endoscopic ultrasound-guided hepaticogastrostomy and the dual-scope gastroenterostomy, as well as images from the follow-up endoscopy 7 months later. 
of the stent was achieved by dilating it with a 15-mm CRE balloon ( $\vee$ Video 1 ).

The patient recovered fully; 7 months later, he has normal bilirubin values and shows no signs of recurrent gastric outlet obstruction. Follow-up endoscopy shows that both stents remain in situ and patent ( $\triangleright$ Fig. 1).

EUS-guided double endoscopic bypass offers minimally invasive and durable palliation [1]. Gastroenterostomy can be performed either with standard devices [2] or with a dedicated double-balloon catheter [1]. The use of a pediatric endoscope alongside the echoendoscope is another way to help stabilize the guidewire during gastroenterostomy, which is a challenging intervention [3].

Endoscopy_UCTN_Code_TTT_1AS_2AG

\section{Competing interests}

None
The authors

Manuel Alejandro Mahler ${ }^{1}$, Robin German Prieto $^{2}$, Inés Oria ${ }^{1}$, Guido Villa-Gómez ${ }^{3}$, Gustavo Vidales ${ }^{3}$, Manuel Perez-Miranda ${ }^{4}$

1 Gastroenterology Department, Hospital Italiano de Buenos Aires, Buenos Aires, Argentina

2 Surgery Department, Hospital central de la policía, Bogotá, Colombia

3 Endoscopy Unit, Instituto de gastroenterología Boliviano Japonés, La Paz, Bolivia

4 Gastroenterology Department, Hospital universitario "Rio Hortega", Valladolid, Spain

\section{Corresponding author}

\section{Manuel Alejandro Mahler, MD}

Gastroenterology Department, Hospital Italiano de Buenos Aires, Perón 4190, C1199ABB Buenos Aires, Argentina manuel.mahler@hospitalitaliano.org.ar

\section{References}

[1] Itoi T, Ishii K, Ikeuchi $\mathrm{N}$ et al. Prospective evaluation of endoscopic ultrasonographyguided double-balloon-occluded gastrojejunostomy bypass (EPASS) for malignant gastric outlet obstruction. Gut 2016; 65: 193 195

[2] Khashab MA, El Zein M, Ngamruengphong S et al. Double endoscopic bypass by using lu- men-apposing stents (with videos). Gastrointest Endosc 2016; 83: 435-439

[3] Tyberg A, Perez-Miranda M, Sanchez-Ocaña $R$ et al. Endoscopic ultrasound-guided gastrojejunostomy with a lumen-apposing metal stent: a multicenter, international experience. Endosc Int Open 2016; 4: E276-E281

\section{Bibliography}

DOI https://doi.org/10.1055/s-0043-119972

Published online: 17.10.2017

Endoscopy 2018; 50: 78-79

(c) Georg Thieme Verlag KG

Stuttgart · New York

ISSN 0013-726X

\section{ENDOSCOPY E-VIDEOS}

https://eref.thieme.de/e-videos

口回 Endoscopy E-Videos is a free 然被 access online section, reporting on interesting cases and new

techniques in gastroenterological endoscopy. All papers include a high quality video and all contributions are freely accessible online.

This section has its own submission website at https://mc.manuscriptcentral.com/e-videos 